\section{Medical network pioneers live 3-D surgical images}

[TOKYO] The world's first live test transmissions of three-dimensional medical images of patients have been launched by Nagoya University in Japan and Duke University Medical Center in Durham, North Carolina, in the United States, using a highcapacity trans-Pacific network.

The experiment is part of the Global Interoperability for Broadband Networks project set up by the G7 group of seven leading nations. Several 'telemedicine' projects already exist in Japan linking hospitals and medical research organizations. The Nagoya-Duke network uses a three-dimensional television system developed at Nagoya that allows reconstruction of stereoscopic images of structures in the human body.

According to Tomohiko Hattori of Nagoya University, who developed the system, several doctors can view the threedimensional images at the same time. Doctors in Japan and the United States can use the network to exchange information about diagnostic and surgical techniques.

The international system is still in its experimental phase. But a telemedicine network developed at the National Cancer Centre in Tokyo is at a more advanced stage.

The national network began operating in April 1994 with a 6-megabit-per-second optical-fibre link between the Tokyo institute and a new campus of the cancer centre in Chiba, $30 \mathrm{~km}$ east of Tokyo. It allows transmission of still high-definition television images such as X-ray images and teleconferencing using the standard NTSC format used in US and Japanese televisions, as well as remote operation of a microscope at the cancer institute.

Six other Japanese cancer centres have since joined the network: the National Sapporo Hospital in the northern island of Hokkaido, Miyagi Prefectural Cancer Center north of Tokyo, Aichi Cancer Center near Nagoya, the National Kure Hospital near

Hiroshima, the National Shikoku Cancer Center in the island of Shikoku, and the National Kyushu Cancer Center in the southern island of Kyushu.

Every week, a lecture-style teleconference is held between the centres to exchange information on diagnostic techniques and treatments for cancer.

About a dozen other medical research institutes, medical associations and hospitals have joined the network with lower capacity links (mainly 64 kilobits per second) allowing them to access databases at the cancer centre. And several more will join next month. In collaboration with Nippon Telephone and Telegraph (NTT) and other telecommunications companies, the National Cancer Centre now has higher capacity 45-megabit and 156-megabit-persecond links between its two campuses.

There are also high-capacity links to the National Cardiovascular Centre in Osaka and the National Institute of Radiological Sciences in Chiba. The transmission of super-high-definition images is now being tested in collaboration with NTT.

Although the cancer centre's telemedicine network is widely used for clinical work, it is still funded as a research project by the Ministry of Health and Welfare on the grounds that it remains 'experimental' and does not come under the national health system.

But the ministry is planning to link 250 hospitals and medical organizations throughout Japan in March in a practical application of networking in medicine. This network, HOSPnet, will have an annual budget of $¥ 3$ billion (US $\$ 24$ million). It will initially have only fairly low-capacity links and most hospitals will use an Internet telephone system for communication rather than teleconferencing. But the ministry has ambitions to upgrade it to a telemedicine network.

David Swinbanks

\section{Top FDA official named as 'de facto' chief}

[WASHINGTON] Michael Friedman, a former US National Cancer Institute official, will become 'de facto' head of the Food and Drug Administration (FDA) later this month, when commissioner David Kessler departs, possibly to become dean at Yale University School of Medicine.

Friedman is currently deputy commissioner for operations at the FDA. His elevation does not indicate that he heads a list of candidates for commissioner, says a spokesman for Donna Shalala, the Health and Human Services Secretary. Shalala is conducting a wide search for candidates, and soliciting "lots" of input from industry, consumer groups, Congress and the medical and scientific communities.

Neither the FDA nor Yale's School of Medicine would comment on reports that Kessler is a leading candidate to become dean of the school. A Yale spokeswoman says Kessler has visited the campus at New Haven, Connecticut, but that "nothing has been settled".

Meredith Wadman

\section{IMAGE UNAVAILABLE FOR COPYRIGHT REASONS}

Precious package: the $\$ 100$-million NICMOS will boost the scientific capabilities of Hubble.

\section{In-filight service will let Hubble see red}

[WASHINGTON] The Hubble Space Telescope will have its vision extended into infrared wavelengths next week when spacewalking astronauts install two new science instruments in the orbiting observatory and refurbish its tape recorders, guidance sensors and other hardware.

"We're replacing 1970s technology with 1990s technology," says Edward Weiler, project scientist for the telescope at the US National Aeronautics and Space Administration (NASA). Although there are risks in tinkering with a spacecraft that is operating perfectly, the payoff will be a "dramatic increase in science throughput", he promises.

One of the new instruments, the $\$ 100$ million Near Infrared Camera and MultiObject Spectrometer (NICMOS), will more than double Hubble's spectral coverage, which at present observes only at visible and ultraviolet wavelengths.

The instrument, a combined camera, spectrometer, polarimeter and coronagraph, will be sensitive in the near infrared range from 0.8 to 2.5 micrometres. Astronomers expect to use it to see some of the youngest objects in the early Universe.

On the fourth day of the space shuttle Discovery's nine-day mission, astronauts will remove two first-generation spectrographs from the telescope and replace them with NICMOS and another new science instrument, the Space Telescope Imaging Spectrograph. This device takes many spectra at once, and so can work 30 to 40 times faster than the instrument it replaces. It will be especially useful for measuring the velocities of material spiralling into black holes.

The instruments will be checked and calibrated after installation, and will not be fully operational for several months. They are already much in demand: NASA received 1,400 proposals from astronomers for the next Hubble viewing 'cycle' - more than for any previous round.

Tony Reichhardt 